\title{
REVIEWS
}

\section{Health financing issues and reforms in Africa}

\author{
Dorjsuren Bayarsaikhan*1, Laurent Musango² \\ ${ }^{1}$ Health Economist, Department of Health Systems Governance and Financing, World Health Organization, Geneva, Switzerland \\ ${ }^{2}$ Regional Adviser for Health Financing and Social Protection, Health System \& Services Cluster, WHO Regional Office for \\ Africa, Brazzaville, Congo
}

Received: February 16, 2016

Accepted: April 17, 2016

Online Published: May 17, 2016

DOI: $10.5430 /$ ijh.v2n2p37

URL: http://dx.doi.org/10.5430/ijh.v2n2p37

\begin{abstract}
Achieving universal health coverage is one of the overarching goals of the 2030 agenda for sustainable development. Health financing is an essential health system component contributory to this goal. In recent years, many African countries initiated health financing reforms to follow the path to universal health coverage. This paper reviews and synthesizes common health financing issues, reforms and challenges in Africa. The paper presents an analytical overview and the ways forward to make health systems financing more equitable, efficient and resilient through universal health coverage oriented reforms in Africa.
\end{abstract}

Key Words: Health financing reform, Health financing strategy, Universal health coverage

\section{INTRODUCTION}

Currently, many African countries are undertaking health systems financing reforms to increase health coverage and financial protection following the path to universal health coverage (UHC). Major health financing reform challenges and progresses have been discussed in various regional and country specific events and occasions such as the 2013 Regional Knowledge Exchange Forum held in Nanyuki, Kenya with support from the World Bank, WHO and other Providing for Health $(\mathrm{P} 4 \mathrm{H})$ network partners. This forum addressed health financing issues, options and reform strategies in 13 Sub-Saharan African countries, namely Botswana, Ethiopia, Ghana, Kenya, Liberia, Malawi, Mozambique, Rwanda, South Africa, Tanzania, Uganda, Zambia and Zimbabwe. Health financing situations, policies, reform strategies and lessons learnt were discussed during this regional event. This paper summarizes health systems financing common issues and reform focuses in these countries. It presents an analytical overview and the ways forward to make health systems financing more equitable, efficient and resilient through universal health coverage oriented reforms. The methods used in this paper include review of country focused presentations, discussions, event follow-up questionnaires, health expenditure data and literature search to complement health financing reforms in Africa.

\subsection{Health financing situation in Africa}

Most African countries recognize a right to health in their national constitutions. ${ }^{[1]}$ Many African countries made notable progress in improving population health outcomes in the last decade. ${ }^{[2]}$ Health is high on their political and development agenda. ${ }^{[3,4]}$ In 2001, heads of African Union countries met in Abuja and pledged to set a target of allocating $15 \%$ of their government budget to the health sector. ${ }^{[5]}$ This was an important call for many governments to orient their health financing reforms to mobilize more monies for health. Since then the proportion of total government expenditures allocated to health increased in many countries like Ethiopia,

\footnotetext{
* Correspondence: Dorjsuren Bayarsaikhan; Email: bayarsaikhand@who.int; Address: Health Economist, Department of Health Systems Governance and Financing, World Health Organization, Avenue Appia 20, 1211 Geneva 27, Switzerland.
} 
Malawi and Rwanda. ${ }^{[6]}$ There are continuing efforts to reach the Abuja target in the region. According to the Global Health Expenditure Database (GHED), the attainment of this target has been fluctuated from two countries in 2004 to nine in 2009 , and then fewer in later years. For example, general government health expenditure as percentage of general government expenditure among the countries participated in the 2013 Regional Knowledge Exchange Forum varies from $6 \%$ in Kenya to $22 \%$ in Rwanda (see Figure 1). To some extent these differences indicate that political will and commitment is critical together with clear vision, health and development priorities to increase government revenue allocation to health. In some situations, political leaders are committed and marked their engagement in health, but countries had constraints to align this political support with budget realities. Therefore, addressing the lack of political will and the disconnect between political commitment and budget constraints rooted in the fiscal space in some countries is still essential to attain the Abuja target.

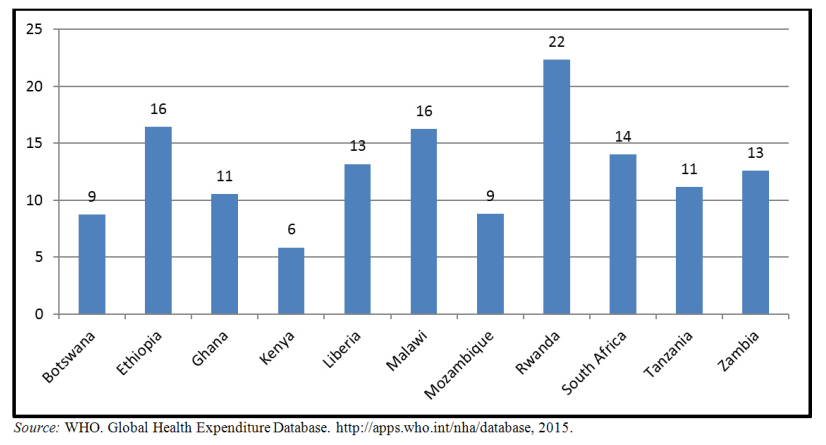

Figure 1. General government health expenditure (GGHE) as \% of general government expenditure (GGE) in 2013

In the broader context of health financing policy and reforms for UHC, the Abuja target is not only pre-defined spending target, but the guide to increase compulsory, prepaid and pooled financing to ensure greater health coverage and financial protection. It also reflects the necessities that health financing reforms need to examine the important link between revenue mobilization, pooling and purchasing functions to translate new revenues into effective health coverage and financial protection, especially in settings with high fragmentation and relatively passive purchasing systems.

In 2014, out-of-pocket payment (OOP) as percentage of total health expenditure (THE) in countries of the WHO African Region was estimated from 5\% in Botswana to $72 \%$ in Nigeria (see Figure 2).

Today OOP is widely known as the main cause not only for inequity in access, but also for household financial catastrophe and impoverishment when it dominates in health fi- nancing. ${ }^{[7]}$ OOP raises serious concerns among policy and decision-makers because of the evidence that high OOP is a big challenge and threat to UHC. The 2010 World Health Report raised an issue of financial protection and empirical evidence on the linkage between the incidence of catastrophic and impoverishing health expenditure and OOP. The report estimates that in most countries there is little financial catastrophe or impoverishment where OOP on average is lower $15 \%-20 \%$ of THE. ${ }^{[8]}$ It means that pre-paid and pooled public financing arrangements rather than direct OOP provide greater protection against financial risk and hardship associated with ill-health and health payments.

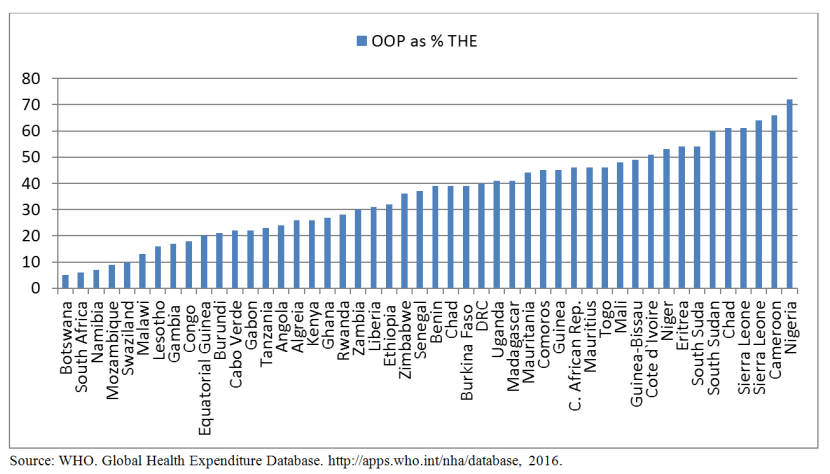

Figure 2. Out-of-pocket payment (OOP) as \% of total health expenditure (THE) in African countries, 2014

Like in many other countries and regions, high OOP is associated with low levels of public financing for health. ${ }^{[9]}$ The lack of public financing often pushed public providers to supplement their budget with various official and non-official fees and charges for publicly provided health services. Health service fees and charges directly paid by households to both not-for-profit and for-profit-private providers are also an issue when private providers individually determine their fee rates.

In some African countries non-profit institutions, nongovernmental and missionary organizations play an important role in health financing and service delivery. They may have different labels, but their common characteristics are that they operate on a non-profit basis serving households and providing some degree of financial protection. For example, private not-for-profit facilities in Uganda play a significant role in health care provision to the disadvantaged population and reduction of user fees. ${ }^{[13]}$ This might be one of the reasons that in some countries direct household OOP as percentage of THE is relatively low compared to private health expenditure (PvHE) as percentage of THE (see Figure 3).

But due to methodological and other reasons, it is possible that OOPs are not fully captured and reflected in these esti- 
mates or low OOP numbers are hidden in PvHE associated with large inequalities. For example, PvHE accounts for the largest share of THE in South Africa due to private (voluntary) health insurance that covers less than $16 \%$ (mainly high and middle income people) of the population. ${ }^{[14]}$ Therefore, this pattern of PvHE needs further analysis and policy discussions in individual country settings to better understand their major drivers and impacts on health coverage, equity and financial protection.

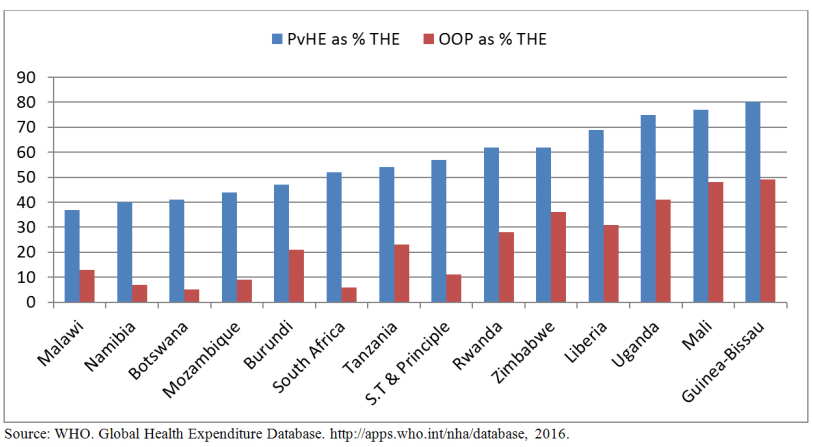

Figure 3. Private health expenditure (PvHE) and out of pocket payment (OOP) as \% of total health expenditure (THE) in 2014

As a policy response there are ongoing initiatives to control and reduce OOP and support health care initiatives by introducing user fee abolishment and fee exemption policies for essential health services such as maternal, child and reproductive health services. But these policy initiatives need coherent link and support across health financing arrangements. For example, free health care initiative aims to allow people to access essential health services without or less financial barriers associated with both formal and informal fees, however, it requires additional funds to eliminate or substitute these fees. A national free health care policy at primary and secondary levels of care in Liberia was supported with additional public revenues to effectively address the largely underfunded health system that relied on informal payments and resulted in limited coverage, weak service delivery and quality. The new policy in Liberia enabled to improve health care coverage and health service utilization by reducing OOP below $30 \%$ of THE. Currently user fee abolishment and free health care policies are well accepted and implemented in many other African countries like Burundi, Ghana, Uganda and Zambia. ${ }^{[15-17]}$

Health insurance is considered as an option to raise and pool revenues, as well as provide some degree of financial protection in several African countries. Although it has some potential, especially when health insurance coverage and contribution is compulsory by law, several policy issues are

Published by Sciedu Press raised and discussed in recent years. One of them relates to its limitations to cover non-salaried employees who are the largest population contingent engaged in the informal sector in most countries. In some situations, community based health insurance (CBHI) is promoted as a mechanism to fund health services and provide financial protection for people working in the informal sector. ${ }^{[10-12]}$ But limitations exist to expand population, health service benefit and cost coverage because of its voluntary enrollment and weaknesses to offer a broad range of health service benefits and effective financial protection due to low contribution rates, irregular payments and frequent drop-outs. Phased strategies to cover different groups such as civil servants, formal public and private sector employees and non-salaried workers largely resulted in fragmented pools with different revenue potentials and benefits. In most cases low-income, poor and vulnerable population, who cannot contribute have been excluded from insurance coverage. Some African countries succeeded with health insurance and expanded insurance coverage using non-contributory revenues such as value added tax, state subsidy for contribution payment and public budget transfers to overcome the above mentioned challenges.

Currently, compulsory health insurance is practiced in Algeria, Gabon, Ghana, Kenya, Mali, Rwanda, Tanzania and Togo. Almost all health insurance schemes in these countries receive public subsidies or budget transfers. Mandatory insurance is discussed over many years in Benin, Swaziland, Uganda and Zambia, but policy consensus and decisions are still not reached yet. Ethiopia passed a decree on compulsory health insurance, but its implementation had lengthy delays mainly because of administrative capacity to implement the decree. Other private and CBHI options are also practiced in the region, but their scale is low except Rwanda that made health insurance coverage mandatory by law since 2015 . The law strengthened communities to form the base of the bottomup pillar of the health system with strong involvement and budget support of central and local governments. This makes the Rwandan health insurance system highly subsidized to cover more people, provide quality health service benefits and strengthen financial protection.

These and other country experiences suggest that health financing reform for UHC in most countries need to aim at raising public revenues to primarily cover the most needy, disadvantaged and excluded population groups. The revenues can come from direct and indirect taxes, non-tax revenues and external sources. ${ }^{[18]}$ Mandatory health insurance contribution can also be considered as an option to expand public revenues, as well as to promote social solidarity and crosssubsidization among the population. But limitations will exist to cover large population beyond contributing members 
unless health insurance receives targeted government (public) subsidies and budget transfers to cover non-contributing members including the poor and disadvantaged. This may change the traditional view on social health insurance and the link between contribution and benefits. It can increase health insurance potential to play a greater role in making progress towards UHC, if all revenues (contributions, subsidies and budget transfers) are efficiently pooled and effectively used to purchase legally defined, quality health service benefits from public and private providers for all members.

As mentioned above, the African region already offers some good examples of compulsory and prepaid sources of financing that do not derive from traditional insurance-based contributions. For example, Ghana social health insurance is predominantly funded with value added taxes pooled at national level. The system needs income graded, progressive contributions from enrolled members to supplement the revenue while maintaining equity for low income pensioners, children below 18 years old and pregnant women who are currently exempted from contribution payments. Gabon launched a national health insurance program in 2007 with public funding support to cover a larger segment of its population. Because of the government's policy objective to achieve UHC, public sector resources were almost doubled between 2008-2012. Budget allocations for health increased to $7.2 \%$ by 2012 , and as much as $27 \%$ of public financing allocated to the national health insurance program. ${ }^{[19]}$

High dependency on external funding, its unpredictability and volatility make health systems financing fragile and unstable to firmly support national health policies and plans (see Figure 4). Liberia experiences a limited budgetary support from the government coupled with declining contributions from external sources. Unpredictable external sources in Malawi cause substantial challenges for government health budget, which has been identified insufficient to meet population health needs. In Mozambique many large health programs are funded by the Global Fund, World Bank and GAVI. These funding mechanisms have contributed to health systems financing, although they were not always predicable and stable sources of funds. According to the Ugandan National Health Accounts report, external financing accounted for $41 \%$ of the total health sector budget and the rest was funded domestically with dominant private OOP financing. ${ }^{[20]}$ In Zambia external funding still plays a vital and essential role in financing and providing essential health services to the population.

All these experiences suggest that African countries use different sources of finance and various options to pool revenues at national or sub-national levels. Their recent focus on UHC strengthens their reforms to increase prepayment, pooling and redistribution of funds while aiming to reduce direct OOP.

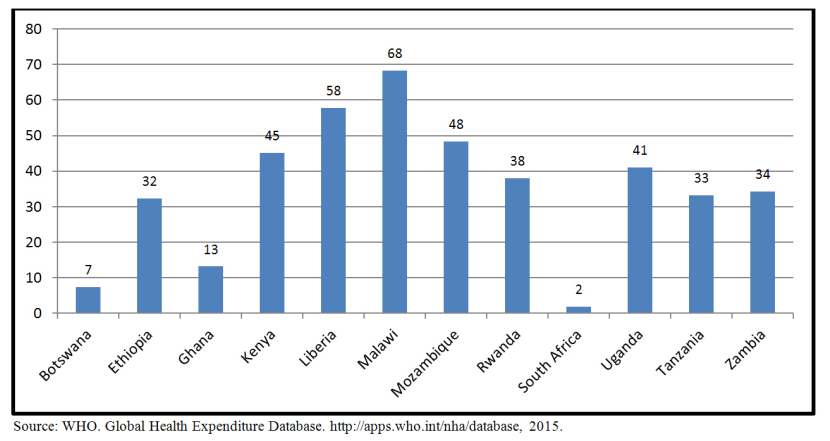

Figure 4. External resources on health as \% of THE in selected African countries

\subsection{Main challenges}

There are several health financing issues, concerns and challenges, which are common to many African countries. Primarily, they refer to the adequacy of public financing and the challenge to protect, maintain and increase government revenues for health. In recent years, government decisions on reallocating public budgets led to reductions in allocation of general revenues to health in Botswana, Mozambique, Tanzania and Zambia. The main challenge in Botswana was to manage economic pressure to reduce government expenditure on health due to reduced government revenues and increased budget deficit. Limited public financing mainly created supply-side constraints and increased gaps in healthcare coverage and utilization in Zambia. It is observed that not only long distances to travel, but also stock-outs of essential medical supplies due to budget constraints together with insufficiently organized, trained and motivated health workers were the main cause for low service utilization. ${ }^{\text {[21] }}$

Table 1. User fee abolition in Uganda

\begin{abstract}
1999/2000, 2002/03 and 2005/06 were used to investigate the impact of user fee abolition on the attainment of universal coverage objectives. An increase in utilization was registered in the period immediately following the abolition of user fees and was most pronounced in the poorest quintile. In the context of expenditure, the total annual average expenditures on health per household remained fairly stable between the 1999/2000 and 2002/03 surveys. There was, however, an increase of US\$21 in expenditure between the 2002/03 and 2005/06 surveys. Abolition of user fees improved access to health services and efficiency in utilization. On the negative side, financial protection is yet to be achieved. Out-of-pocket expenditure remains high and mainly affects the poorer population quintiles.

Note. Source: Juliet Nabyonga J, et al. Abolition of user fees: the Uganda paradox. Health Policy and Planning, 2011.
\end{abstract}

OOP is a policy concern because of its regressive nature and negative impacts on equity, access, use of health services, as 
well as household catastrophic health expenditure and impoverishments in Africa. Currently, not all health systems are able to review, estimate, report and monitor OOP on a regular basis. For example, health financing reviews in Mozambique are limited to the national health system and public financial resources managed within the Ministry of Health. In Zambia OOP makes the health system highly inequitable since it is incurred by the poor and sick, rather than the rich and healthy.

Table 2. Ghana National Health Insurance Scheme (NHIS)

High political commitment and innovative policy choices
resulted in adoption of National Health Insurance Act in 2003,
which established the NHIS in Ghana. It covers the basic health
needs of the population with a predefined benefit package that
aim to address $95 \%$ of the disease burden in Ghana. About $80 \%$
of NHIS fund is formed through a mandatory health insurance
levy added to the standard rate of value added tax (VAT) and the
remaining $20 \%$ is collected from its beneficiaries. The NHIS has
enabled to make significant advances in moving away from direct
OOPs. Along with many successes, the NHIS also needs to
overcome a number of challenges, which include law
enforcement and compliance, especially among informal sector
employees. According to NHIS data, about $54 \%$ of Ghana` 24
million people are recorded as active members. Moreover,
population coverage and health care cost increases require greater
financial sustainability and efficiency of resource use.
Nevertheless, Ghana`s experience showed that health financing
reforms can combine revenues from taxation (VAT) and
compulsory social health insurance contributions into a single
national pool rather than relying on different schemes leading to
fragmentations, inequities and inefficiencies.
Note. Source: Success Stories of Health Financing Reforms for Universal Coverage, Ghana. WHO 2011.

Another challenge in Africa relates to health insurance design, practice and other factors associated with household income levels, the overall economic structure, revenue base and administrative capacity to cover the population engaged in the informal economy including the poor, low income and vulnerable. Sometimes, health insurance is discussed as a health financing policy option for UHC, which is not the case in all settings. The study conducted by WHO/AFRO and the African Health Economics and Policy Association (AfHEA) on the needs of capacity building in universal coverage for policy makers in Africa shows that health insurance mechanisms in Africa are largely fragmented in terms of population coverage, revenue collection, pooling and purchasing. ${ }^{[22]}$ The study suggests that health insurance reform and design should aim to reduce these fragmentations to avoid difficulties in pooling risks, funds and merging different health service benefits afterwards. Public subsidies and budget transfers often weaken the link between health insurance contribution and health services that allow to expand health coverage and benefit provision on the basis of citizenship.

Lack of effective governance, regulatory mechanisms and institutional capacity results in inadequate health coverage, financing and service delivery arrangements. In Kenya, Malawi, and Uganda it is mixed with inequitable and inefficient resource allocation, poor transparency and accountability at national and district levels. ${ }^{[23]}$ Health system and financing reforms in some countries aim to address this concern. Introduction of performance-based financing with free health care policy initiative in Burundi had positive impacts on improving accountability of health care facilities for delivering quality and priority maternal and child health services. ${ }^{[24]}$

Table 3. Managerial autonomy and community ownership in Rwanda

The Rwandan health system managed to encourage managerial autonomy and community ownership while enabling the national authorities to retain a large degree of control, elaborating legislation, policy and strategy, ensuring monitoring and evaluation and also regulating the health sector. The communities in Rwanda form the base of the health system. Communities play a key role in making decisions by local governments and the management of health facilities including verification of activities reported by health facilities under performance based financing. The communities also give feedback on the quality of health services provided. The active role played by the communities in Rwanda has also assured significant adherence to the policies, while reinforcing the accountability and transparency of the health financing system as a whole.

Note. Source: Success Stories of Health Financing Reforms for Universal Coverage, Rwanda. WHO 2011.

Health financing reforms for UHC also need to be coherent and supportive of other reform measures designed and implemented in other parts of the health system. ${ }^{[25]}$ For example, the government of Ethiopia successfully scaled up the health workforce to provide high impact primary care and community based services by creating health extension workers, shifting tasks, and expanding primary health care units. Increased production of mid-level health professionals and general practitioners trained to provide priority and cost effective interventions have been successfully deployed to areas where they are most needed. ${ }^{[26]}$ South Africa is implementing a national drug policy which improves the selection, procurement and use of essential medicine both in the public and private sectors. It supports integrated policy actions, supportive environment, ownership, transparency, and monitoring and evaluation mechanisms that increase the availability and accessibility of essential medicine to all 
citizens at low cost through a primary health care network. ${ }^{[27]}$

Although external funding plays a critical role in some countries, it can be an issue for medium and long-term planning where it accounts for a large share in national health budget like in Liberia, Malawi, Mozambique and Uganda. Besides unpredictability and volatility, external funds are often not harmonized or aligned with government priorities. Some studies suggest that only about $20 \%$ of all health aid is given as general budget support to implement government's health programme. ${ }^{[28]}$ Efficiency is another concern when external assistance creates parallel funding channels, duplicated management and procurement units, and uncoordinated project activities. To address these issues, the Democratic Republic of Congo (DRC) implemented health system strengthening reform since 2005 that supported a national coordination mechanism and single operational district plans with multidonor inputs. As part of the reform, the government established a national procurement system to pool resources for medicine supply and distribution, which demonstrated positive results and successes in terms of reduced fragmentation, duplication, program management cost and mobilization of new domestic resources for health along with efficiency savings. [29]

Finally, fragile states, post-conflict and post-Ebola countries present specific challenges. Their fiscal capacity to increase revenue from domestic revenue sources is very low for the foreseeable future. ${ }^{[30]}$ Accordingly, they will remain largely dependent on external financial assistance and their governments will work under pressure to efficiently scale-up basic inputs and build the foundation of their health systems to ensure effective access to essential health services to meet their population health needs.

\subsection{Ways forward}

Health financing reform policy and strategies in African countries are largely guided by the concept of UHC. They adopted the concept with the aim of making their health system and financing resilient and stable along with the core policy dimensions provided in the World Health Report 2010. These relate to health coverage and strategic actions to raise sufficient resources for health, remove financial risks and barriers to access, and promote efficiencies and eliminate resource waste.

Although each country situation is unique and different, country level initiatives encompass a similar process that supports health financing analytical, technical work, evidenceinformed policy dialogues, awareness campaigns, related organizational and administrative actions, and multi-sector involvement. The process contributes to the development of evidence-based inter-governmental and international consultative mechanisms and multi-sector and multi-agency partnerships to ensure that health financing strategies address and lessen the existing weaknesses and constraints related to healthcare coverage, financial protection and efficiency in resource use. Current health financing reforms in many African countries aim at addressing under-funded health services, poor quality of health care, high OOP expenditure, low utilization of health care and poor health outcomes due to high unmet population health needs.

In relation to underfunded health services, efficient use of available resources, raising additional revenue for health through innovative and integrated financing reforms and options including sin tax, specific levies on value added taxes, payroll taxes, as well as strengthening public-private partnerships are commonly discussed to increase health resources and to reduce OOP expenditure. In some African countries, increased public revenues are used to support free health care policies for essential services or targeted population with waiver and fee exemption mechanisms. Below box shows specific reform focuses for selected African countries.

Table 4. Country specific health reforms

Botswana`s health reform focus is efficient use of available resources in
the public and private sectors together with raising additional revenues.
Ethiopia gives more emphasis on fee exemption policy and revenue
mobilization through health insurance and expansion of health service
provider autonomy within their reform. Kenya strategically aims to
reform its national hospital insurance fund and introduce contribution
subsidy programs for the poor. The Ministry of Health in Mozambique
promotes the option to develop a package of essential healthcare and
make it universally available and accessible. Tanzania prioritized
government policy interventions to support free maternal and child
services. Similarly, the Zambian government gives the highest priority to
free and universally accessible primary healthcare services for all citizens.
Uganda is shifting its policy focus from resource mobilization to resource
organization, pooling, purchasing, sustainability, equity, and efficiency
improvements in their health financing arrangements.
Note. Source: Country updates from Nanyuki forum participants, 2014.

Considering both quantity and quality of health services, policy shift and transition from input to output-based financing of health services or result and performance-based financing, and revenue retention at facility levels are largely supported, but their actual implementation needs proper regulation and oversight mechanisms.

Service delivery reform initiatives to increase utilization of quality health services are discussed in many African countries with an emphasis on high population health impact interventions such as maternal, new born and child health services, prevention of non-communicable and communicable diseases. This involves investments in facilitating policy dialogues and strategic innovations to tackle the social deter- 
minants of health by bringing together all relevant stakeholders and sectors (including the ministries of finance, labour and social affairs), communities, civil society organizations and the private sector.

In addition, African countries are convinced that investing in health is not only about the volume of resources. It should strengthen all health system components in a synergic manner to ensure adequate human resources for health, community based services and improve health service infrastructure, centralized and decentralized administration to build resilience and capacities for policy and strategy development and implementation including civil registration, vital statistics and health information, and critical logistics and supply systems.

In some countries, a decentralization plan is supported to meet local healthcare needs and improve catchment population coverage. This requires coherent and consolidated efforts from central and local governments because large population coverage is feasible only with predominant public financing, budget transfers and subsidies managed at national and sub-national levels. In relation to social health insurance, efforts will be needed to avoid fragmentations in coverage of salaried employees in the public and private sectors and citizens engaged in the informal sector. Health coverage extension to the poor and vulnerable that are currently excluded from health insurance should come at the center of health financing policy and priority. All these efforts and reforms will need good governance in public finance management, leadership, evidence and institutional capacities to meet their UHC related policy objectives.

\section{Conclusion}

African countries are increasingly convinced that health financing arrangements for UHC should provide population wide coverage and equal access to needed health services, especially for the poor and vulnerable people. Universal coverage and equal access to comprehensive and quality health services for all people without fear of paying for them consistent with the concept of UHC is a major policy focus in Africa. The UHC policy focus increases political commitment to improve health financing arrangements, administrative and technical capacities to design and implement a realistic strategy to ensure more stable, equitable, effective and efficient health financing systems in their own context. National health financing reform efforts and initiatives also broaden opportunities for effective partnership collaboration. These initiatives largely promote coherent, coordinated and focused collaboration and inputs to strengthen country health systems, which are responsive and resilient to address existing challenges. The UHC concept forms a solid ground for African countries to improve their health financing in support of the 2030 development agenda. Today, many African countries have developed their own roadmap to formulate, promote, implement, monitor and evaluate health financing reforms for UHC. In the near future, the world can learn from an extensive body of knowledge, evidence, experience and best practices created in Africa in reforming health systems finance for UHC in various socioeconomic settings.

\section{ACKNOWLEDGEMENTS}

The authors are grateful to health system and financing country experts, who participated in the event follow-up exercise organized in 2014. Special thanks to Joy de Beyer, who contributed to the development of regional knowledge exchange forum follow-up questionnaire and Hélène Barroy, Inke Mathauer and Joseph Kutzin who provided valuable comments on this paper.

\section{CONFlicts OF INTEREST Disclosure}

None declared.

\section{REFERENCES}

[1] Global Health and Human Rights Database. http: //www.globalhealthrights.org/constitutions/con stitution-region/page/2/ Accessed 09 April 2016.

[2] World Health Organization "s Regional Office for Africa: The health of the people, what works. The African Regional Health Report. 2014.

[3] African Union. 2007. Africa Health Strategy. 2007-2015. Available from: http://www.nepad.org/system/files/AFRICA HEALTH_STRATEGY\%28health\%29. pdf Accessed 11 April 2016.

[4] African Union. 2016. Africa Health Strategy 2016-2030. Available from: http://au.int/en/document/africa-health-s trategy-2016-\%E2\%80\%93-2030 Accessed 11 April 2016.
[5] Abuja Declaration. Nigeria, April 2001.

[6] World Health Organization: The Abuja Declaration: Ten years on. 2011. Available from: http://www.who.int/healthsyst ems/publications/abuja_report_aug_2011.pdf?ua=1. Accessed 09 Nov 2015

[7] Leive A, Xu K. Coping with out-of-pocket health payments: empirical evidence from 15 African countries. Bulletin of the World Health Organization. 2008; 86(11), 849-56. http://dx.doi .org/10.24 71/BLT. 07.049403

[8] WHO: Health Systems Financing. The path to universal coverage. World Health Report. 2010; 97-99.

[9] Kutzin J, Yip W, Cashin Ch. Alternative financing strategies for universal health coverage. World Scientific Handbook of Global Health 
Economics and Public Policy. 2016; 267-309. http://dx.doi.o rg/10.1142/9789813140493_0005

[10] Carrin G, Waelkens MP, Criel B. Community-based health insurance in developing countries: a study of its contribution to the performance of health financing systems. Tropical Medicine and International Health. 2005; 10(8): 799-811. PMid: 16045467. http://dx.doi.org/10.1111/j.1365-3156.2005.01455.x

[11] Ekman B. Community based health insurance in low-income countries: a systematic review of the evidence. Health Policy and Planning. 2004; 19(5): 249-70. PMid: 15310661. http://dx.doi.org/10 1093/heapol/czh031

[12] Wang H, Pielemeier N. 2012. Community-Based Health Insurance: An Evolutionary Approach to Achieving Universal Health Coverage in Low-Income Countries. Journal of Life Sciences. 2012; 6: 320-9. Available from: http://abtassociates.com/AbtAssociates/ files/d9/d9c35de1-22d5-497f-8b19-9334865b0a9e.pdf Accessed 11 April 2016.

[13] Ministry of Health, Uganda. 2010. A Health Financing Review. Available from: http://www.who.int/health_financing/doc uments/hsfr_e_10-uganda.pdf?ua=1 Accessed 11 April 2016

[14] Borghi J, Ataguba J, Mtei G, et al. Health financing in South Africa. CME, 2010; 28(2). Available from: http://cmej .org.za/inde $\mathrm{x} \cdot \mathrm{php} / \mathrm{cmej} /$ article/viewFile/1782/1466 Accessed 10 April 2016.

[15] Sibomana S, Reveillon M. Performance based financing of priority health services. Burundi background paper. WHO. Improving health system efficiency, 2015. Available from: http://www. who.int/ health_financing/topics/efficiency-cost-effective ness/Efficiency_health_systems_Burundi/en/ Accessed 14 Nov 2015

[16] Masiye F. et al. Removal of user fees at primary health care facilities in Zambia: a study of the effects on utilization and quality of care. Harare. Regional Network for Equity in Health in east and southern Africa, 2008

[17] Riddie V, Robert E, Meessen B. Les pressions exercées par l'abolition du paiement des soins sur les systémes de santé. World health report 2010 background paper, no. 18 .

[18] Jowett M, Kutzin J. Raising revenues for health in support of UHC: Strategic issues for policy makers. Health Financing Policy Brief. WHO. 2015. Available from: http://www.who.int/health_f inancing/documents/revenue_raising/en/ Accessed 01 Dec 2015.

[19] Saleh K, Couttolenc BF, Barroy H. Health Financing in the Republic of Gabon. World Bank Study. 2014. Available from: http: //documents.worldbank.org/curated/en/2014/09 /20274030/health-financing-republic-gabon Accessed 16 Dec 2015.

[20] Ministry of Health, the Republic of Uganda: National Health Accounts FY 2008/09 and FY 2009/10. 2013.

[21] Kamanga M. Zambia team response to 2013 Kenya Forum follow-up questionnaire collected by WHO. 2014.

[22] AFHEA-WHO: Report on data for capacity building in universal coverage for policy makers in Africa. 2013

[23] Kenya, Malawi, and Uganda team responses to 2013 Kenya Forum follow-up questionnaire collected by WHO. 2014.

[24] WHO. 2011. Success Stories of Health Financing Reforms for Universal Health Coverage. Providing for Health. Burundi. Available from: http://www.fbpsanteburundi.bi/cside/contents/ docs/Success_stories_of_helth_financing_reforms_fo r_universal_coverage.pdf Accessed 11 April 2016.

[25] WHO. 2007. Everybody's business. Strengthening health systems to improve health outcomes. WHO's framework for action. Available from: http://www.who.int/healthsystems/strategy /everybodys_business.pdf Accessed 11 April 2016.

[26] Alebachew A, Waddington C. Human Resources for Health Reforms. Ethiopia background paper. WHO. Improving health system efficiency. 2015 Available from: http://www.who.int/health _financing/topics/efficiency-cost-effectiveness/E fficiency_health_systems_Ethiopia/en/ Accessed 20 Nov 2015.

[27] Gray A, Suleman F, Patel A, et al. Implementation of reforms under the National Drug Policy. South Africa background paper. WHO. Improving health system efficiency. 2015. Available from: http://www.who.int/health_financing/topics/effici ency-cost-effectiveness/Efficiency_health_systems _South_Africa/en/ Accessed 20 Nov 2015.

[28] WHO. 2007. Aid effectiveness and health. Working paper No 9. Available from: http://www. who.int/healthsystems/gf3.pdf Accessed 11 April 2016.

[29] Ntembwa H, Lerberghe W. Improving aid coordination in the health sector. DRC background paper. WHO. Improving health system efficiency. 2015. Available from: http://www.who.int/heal th_financing/topics/efficiency-cost-effectiveness /Efficiency_health_systems_Congo/en/ Accessed 23 Nov 2015.

[30] WHO. 2016. Sustaining universality and security through Health System Strengthening. An agenda for attaining the SDGs, 2015-2030. A WHO internal working document. 